\title{
The diagnosis of diabetes mellitus
}

\author{
H. KEEN
}

The clinical syndrome of diabetes mellitus, presenting with or without symptoms, and progressing to the seemingly unavoidable morphological changes in eyes, kidneys, nerves, and blood vessels, is too well known to need repetition. The classification of the syndrome is shown in Table I, and requires only

\section{TABLE I}

\section{HYPERGLYCAEMIA}

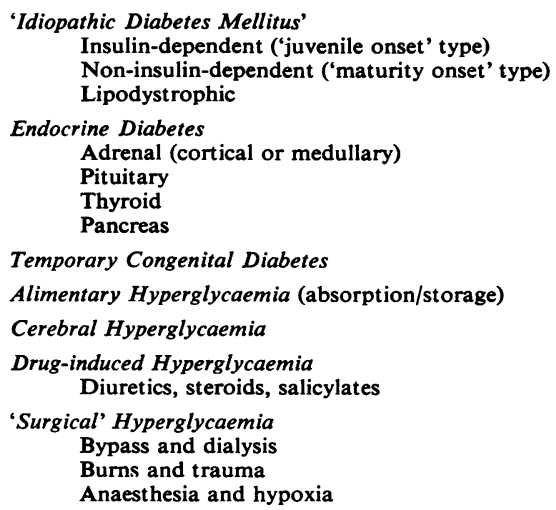

a brief rehearsal as it is well described in the many excellent textbooks on diabetes mellitus. The nature of the link between the insulin-dependent (or juvenileonset) type of 'idiopathic diabetes' and the commoner non-insulin-dependent (or maturity-onset) type continues to attract much research but there is no decisive new information to report. The endocrine syndromes still take us unawares and temporary congenital diabetes would probably be less rare if looked for more often in the newborn. The widely fluctuating glycaemia of the so-called 'alimentary' group with abnormally high peaks and abnormally low troughs of blood sugar superimposed on an essentially normoglycaemic background is readily recognized. There has been little advance since Claude Bernard in explaining the hyperglycaemia following cerebral lesions. An increasing number of drugs and physical procedures have diabetogenic potential and these, like the other items on the list, are competently dealt with by current texts.
My task is to deal, not with florid clinical syndromes, but with an examination of the minimal criteria necessary for the diagnosis of diabetes, a problem which is of much less importance in a diabetic clinic than in a population survey where it constitutes the very raison d'être. I propose, first, to review some of the 'non-glycaemic' factors which have been presented as central to the diabetic state and to consider their diagnostic value, but I do so with a deeply lodged prejudice that what really counts diagnostically is elevation of the blood sugar level; I shall deal with that last.

Is there a structural abnormality of the wall of the small blood vessel which accompanies, antedates, or even causes the overt metabolic changes of diabetes? There was considerable controversy on this score during the era of light microscopy and the techniques of classical histopathology (Marble, 1967); further impetus was provided by the advent of the electron microscope and many early claims were made to have demonstrated basement membrane thickening in the capillaries of recently diagnosed diabetics and even of pre-diabetics. It soon became clear, however, that the selective methods of classical histopathology were not appropriate to the solution of this problem and that valid sampling, measuring, and statistical procedures should be employed. The present situation is best summarized by two excellent representative studies employing such procedures. Osterby Hansen (1965) made electron microscopic studies of renal biopsy material taken from young diabetics of very recent onset and from a group of comparable normal subjects. Setting strict criteria to ensure that the vessels studied were cut transversely and selecting standard regions of the vessel wall, she made multiple measurements of basement membrane thickness in the peripheral capillary loop of greatly magnified glomeruli. When the frequency distributions of these width measurements were compared, they were the same for diabetics and normals, with a modal value of about $3,000 \AA$. Nor was there a statistically significant difference when renal biopsy was repeated in the diabetics soon after metabolic stabilization had been achieved. It would seem unlikely that basement membrane thickening precedes the diabetes if it is not demonstrable at the time of clinical onset. 
However, Siperstein, Unger, and Madison (1968) applied similar techniques to the measurement of the basement membrane of muscle blood vessels and found thickening in a group of genetically prediabetic subjects, offspring of diabetic couples, and unaffected twins of established diabetics compared with normal controls. There was, however, considerable overlap between the two groups and some doubt about the metabolic normality of the prediabetics. As will be discussed later, there may be considerable loss of glucose tolerance during the course of the day, particularly in people with lesser disturbances of blood sugar control; it is crucial to establish that scrupulous metabolic normality exists to support the claim that morphological change precedes diabetes. Whichever way this controversy is resolved, it seems unlikely that biopsy will be useful as a primary diagnostic procedure though the possibility remains that some simple functional test indicating altered permeability of the vessel wall could be devised.

The finding of a reliable biochemical marker of diabetes would be a matter of considerable diagnostic importance. Blood group distributions have offered little help but the studies by Kamarit and Laxová (1966) of the pattern of salivary and pancreatic amylase in blood and urine suggest the possibility of a characteristic deviant pattern in juvenile diabetics. There is not yet enough information to judge the possible diagnostic potential of this approach.

It has been claimed, particularly by Vallance Owen and his collaborators (1964), that so-called 'idiopathic diabetics' are defined by the presence of supranormal concentrations of a factor associated with plasma albumin (hence termed synalbumin). This extracted material antagonizes the effect of added crystalline insulin on the rat hemidiaphragm. About $25 \%$ of the population are alleged to carry this trait which appears to be inherited as a mendelian dominant character. However, both the methodology and the interpretation of the synalbumin hypothesis remain controversial, in particular the status of metabolically normal but 'synalbuminpositive' individuals. There is as yet no information to suggest that they are more likely to develop clinical diabetes than 'synalbumin-negative' people, nor is it clear from the published evidence that subjects can be classified into two distinct groups on the basis of high and low synalbumin levels. With the technical difficulties of the extraction and assay procedures and the variation in results among different workers using ostensibly the same techniques (Keen, 1963; Keen and Jarrett, 1967), the study of synalbumin remains a research procedure without a diagnostic role.
Much of the inte:est in insulin antagonism as a causal factor in diabetes stemmed from the demonstration of raised levels of circulating insulin in early diabetics and prediabetics (Yalow and Berson, 1960; Steinke, Soldner, Camerini-Davalos, and Renold, 1963). It has always been difficult to assess to what degree this hyperinsulinaemia was evoked by insulin antagonism and to what degree it was a simple consequence of the raised blood sugar level usually present. Some elucidation of this problem has been provided by the elegant experiments of Perley and Kipnis (1967). By a monitored intravenous glucose infusion they produced normal and diabetic blood sugar curves in a group of normals and also in a group of diabetics. At any given concentration of blood sugar, plasma insulin levels in the non-diabetics were considerably higher than in the diabetics. When obesity was present, whether in diabetics or normals, equivalent blood sugars elicited markedly higher plasma insulin levels than in subjects of normal weight of the same group. The insulin response in the diabetic was therefore inappropriately low in relation to the blood glucose level; it was also lower than normal in relation to the quantity of glucose infused to produce a standard curve, so that the 'effectiveness' of insulin was significantly higher in the diabetic.

There have been several other attempts to identify a fundamentally diabetic pattern of response, not in the behaviour of the blood sugar itself, but in its relation to accompanying plasma insulin values. Pyke and Taylor (1967) studied the plasma insulin levels in oral glucose tolerance tests in the nondiabetic but otherwise identical twins of diabetic patients. In comparison with normals, and at comparable levels of blood sugar, they found lower levels of circulating insulin in these potential diabetics, again suggesting enhanced insulin effectiveness rather than interference with its action. A sophisticated approach to this question has been made by Cerasi and Luft (1967). Following an intravenous loading dose, glucose was infused intravenously at a standard rate for an hour and plasma glucose and insulin were measured for a further two hours. According to Cerasi and Luft, the most important parameter describing the complex glucoseinsulin relationship was the factor $K_{i l}$, indicating the initial insulin response. On the basis of the $\mathbf{K}_{11}$ values in normal subjects and in established diabetics, they distinguished what they termed 'high' and 'low' insulin responders. The normal identical twins of diabetics have low $K_{i 1}$ values but so, also, do about a quarter of ostensibly perfectly normal subjects. Whether it is from their ranks that the diabetics of the future will be recruited remains to be seen. 
These findings are very interesting but it is clearly too early in the day to introduce multiple measurements as complex as these into diagnostic practice. Our main, in fact our only, diagnostic tool remains the glucose tolerance test (GTT). There is no convincing evidence that the intravenous glucose tolerance test is, diagnostically, any more helpful or reproducible than the much more familiar oral test. Steroid-modified glucose tolerance tests and tests based upon blood sugar depression by sulphonylureas are still experimental procedures and have only a limited place in individual diagnosis (Keen and Jarrett, 1969). Considering the important role of the oral glucose tolerance test it is surprising how few critical studies of the test have been made. The most comprehensive is the reproducibility study of McDonald, Fisher, and Burnham (1965), who conducted six oral glucose tolerance tests on each of 334 inmates of a US Federal prison. Although the group as a whole was remarkably reproducible from occasion to occasion, this was far from true for the individuals who composed it. From the six results for each individual, they were able to calculate his individual standard deviation. The considerable variability in the glucose tolerance test can be gauged from the fact that, for example, at the one-hour time point, the median variation was plus or minus 34 $\mathrm{mg} / 100 \mathrm{ml}$ and that in $20 \%$ of the prisoners, the variation exceeded even this very high figure. ${ }^{1}$ The degree of variability correlated with none of the factors they studied-weight, family history, age, etc-apart from the height of the blood sugar level itself, and that at a low level of correlation. Using three sets of locally accepted diagnostic criteria for diabetes, 31 , or about $10 \%$, of the men had one or more tests qualifying him for the diagnosis. None was positive in all six tests; most positives were so in one or two of the six tests only. This study needs careful confirmation, for clearly its relevance to the diagnostic criteria applied to individuals or en masse in survey work is considerable.

Another factor to be borne in mind in establishing blood sugar 'norms' is the considerable geographical variations in blood sugar behaviour in different populations. On the basis of standardized glucose tolerance testing of reasonably large and representative population samples, West and Kalbfleisch (1966) showed marked differences in the prevalence of hyperglycaemia in Uruguay and Venezuela on the one hand, where it was about twice as high as in Malaya, and East Pakistan on the other where it was about half as high as in Malaya. All of these population prevalences were lower than that in white people on the North American main-

${ }^{1}$ Blood glucose was measured by the AutoAnalyzer with a standard deviation of approximately $1.5 \mathrm{mg} / 100 \mathrm{ml}$. land. Marked differences within a Papuan ethnic group were also reported by Prior, Rose, Harvey, and Davidson (1966). Perhaps the most striking findings of all are on the Pima Indians in the USA suggesting a prevalence of significant hyperglycaemia of about $40 \%$ (Miller, Bennett, and Burch, 1968).

Many factors are known to influence the form of the blood sugar response to oral glucose. The importance of the immediately preceding diet may well have been rather overrated for it appears to be only in those eating less than about $100 \mathrm{~g}$ carbohydrate a day that supplementation really changes the curve. Longer term dietary variations are probably much more important but are only now coming under reasonable experimental scrutiny. Dr Jarrett and I (1968) are studying another source of variation in the glucose tolerance test, the influence of time of day on glucose tolerance, a phenomenon indicated by the work of Roberts (1964) and, more recently, of Bowen and Reeves (1967). Glucose tolerance tests have been performed in duplicate in the morning and the afternoon in normal subjects and in people with 'borderline diabetes' selected from our untreated group in Bedford (Table II). In both groups the afternoon values exceeded the morning values at almost all time points. These mean figures conceal some individuals with very considerable glycaemic swings, in some cases from clearly normal values in the morning to clearly diabetic values in the afternoon. In survey work, therefore, time of day must be taken into account in assessing the significance of blood sugar results. Our results also indicate that a person with a normal, or nearnormal morning glucose tolerance test may spend part of the 24 hours at diabetic levels of blood sugar, a point to be checked before assuming metabolic 'normality'.

While the general stress of this communication has been on blood sugar as the major diagnostic variable and the glucose tolerance test as the best method of 'display', it is probably some other factor or factors linked with the blood sugar which is responsible for the tissue pathology characteristic of diabetes. It was considerations of this sort which led us to examine the relation between the glucose tolerance test, blood insulin levels, and circulating fasting glycerides in 220 healthy employees of the headquarters staff of Beechams Ltd, selected by an age and body weight stratifying procedure from about a thousand who cooperated in a pilot diagnostic survey. In association with Drs Abrams, Jarrett, Boyns, and Crossley (1969, see also Boyns et al, 1969), full oral $50 \mathrm{~g}$ glucose tolerance tests were performed with measurement of sugar and immuno-assayable insulin at each time point and of cholesterol and triglycerides in the fasting sample 
TABLE II

MEAN BLOOD GLUCOSE LEVELS FROM ORAL GLUCOSE TOLERANCE TESTS PERFORMED IN THE MORNING AND AFTERNOON ON NORMALS AND ON BORDERLINE DIABETICS ${ }^{1}$

\begin{tabular}{|c|c|c|c|c|c|c|}
\hline & \multicolumn{3}{|l|}{ Normals } & \multicolumn{3}{|c|}{ Borderline Diabetics } \\
\hline & Morning & Afternoon & $p \triangle$ & Morning & Afternoon & $p \triangle$ \\
\hline Fasting & 85 & 87 & n.s. & 94 & 75 & $<0.05$ \\
\hline $\begin{array}{l}\text { After glucose } \\
30 \mathrm{~min} . \\
60 \mathrm{~min} . \\
90 \mathrm{~min} . \\
120 \mathrm{~min}^{1}\end{array}$ & $\begin{array}{r}142 \\
123 \\
86 \\
72\end{array}$ & $\begin{array}{r}158 \\
151 \\
115 \\
85\end{array}$ & $\begin{array}{l}<0.05 \\
<0.05 \\
<0.05 \\
<0.05\end{array}$ & $\begin{array}{l}161 \\
181 \\
155 \\
117\end{array}$ & $\begin{array}{l}146 \\
202 \\
199 \\
158\end{array}$ & $\begin{array}{l}\text { n.s. } \\
\text { n.s. } \\
<0.05 \\
<0.05\end{array}$ \\
\hline
\end{tabular}

${ }^{1}$ Sex-weighted means expressed as $\mathrm{mg} / 100 \mathrm{ml} \mathrm{p} \triangle=$ probability of meaningless difference; n.s. = not significant.

TABLE III

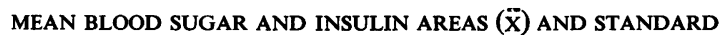
DEVIATION (SD) IN A STRATIFIED SAMPLE OF NORMAL MEN AND WOMEN ${ }^{1}$

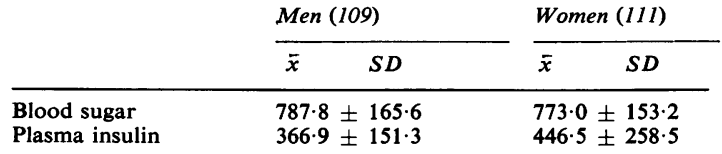

${ }^{1}$ Areas calculated from the formula $a+2 b+2 c+2 d+e$ (where $a$ is the fasting value and $b$ etc. successive values at half-hourly intervals for two hours after a $50 \mathrm{~g}$ oral load) for blood sugar $(\mathrm{mg} / 100 \mathrm{ml})$, and immunoreactive insulin $(\mu \mathrm{u} / \mathrm{ml})$ respectively.

\section{TABLE IV}

CORRELATION COEFFICIENTS BETWEEN BLOOD SUGAR AREA, PLASMA INSULIN AREA, PLASMA FASTING TRIGLYCERIDE AND AGE SHOWN SEPARATELY FOR MALES (M) AND FEMALES (F)

\begin{tabular}{ccll} 
& $\begin{array}{c}\text { Plasma Insulin } \\
\text { Area }\end{array}$ & $\begin{array}{l}\text { Fasting } \\
\text { Triglyceride }\end{array}$ & Age \\
\hline B lood sugar area & & & \\
M & $0 \cdot 32^{2}$ & $0 \cdot 73^{3}$ & $0 \cdot 48^{3}$ \\
F & $0 \cdot 32^{2}$ & $0.38^{3}$ & $0.23^{1}$
\end{tabular}

Plasma insulin area

$\begin{array}{llr}\text { M } & 0 \cdot 30^{2} & 0 \cdot 10 \\ \text { F } & 0 \cdot 21^{1} & -0.08\end{array}$

Fasting triglyceride

$$
\begin{array}{ll}
\mathrm{M} & 0.42^{3} \\
\mathrm{~F} & 0.21^{1}
\end{array}
$$

BSA and IA levels are those shown in Table III. Levels of significance : ${ }^{1} \mathrm{P}<0.05,{ }^{2} \mathrm{P}<0.01,{ }^{3} \mathrm{P}<0.001$

\section{TABLE V}

VALUES OF CORRELATION COEFFICIENT (R) BETWEEN BLOOD SUGAR AREA (SEE TABLE III) AND FASTING TRIGLYCERIDE FOR MALES AND FEMALES UNDER 45 AND 45 YEARS OR MORE

\begin{tabular}{llllll} 
& \multicolumn{3}{l}{ Males } & \multicolumn{3}{l}{ Fem:les } \\
\cline { 2 - 3 } \cline { 5 - 6 } \cline { 5 - 6 } & No. & $r$ & & No. & $r$ \\
\hline-45 & 58 & 0.47 & 59 & 0.09 \\
$45+$ & 42 & 0.82 & 37 & 0.71
\end{tabular}

only. The glucose tolerance and insulin responses were expressed as areas under the tolerance curves. There was little difference between the sexes in the overall mean values of the blood sugar areas (Table III). By contrast, the mean insulin area was significantly higher in women than in men. Table IV shows the simple linear correlation coefficients between a number of the factors measured in the study for men and women separately. The blood sugar area correlates remarkably closely with the fasting triglyceride, particularly in men, where the correlation is high enough to be of predictive value. A further analysis of the effect of age on this relationship in the two sexes is shown in Table V. In the subjects aged 45 or more, the high degrees of correlation are similar for both sexes. Below that age, however, there is marked dissimilarity; although the correlation in the younger men is fairly substantial, it is non-existent among the younger women. The precise meaning of this very close relationship between blood sugar response and fasting triglyceride levels remains to be worked out, but it is difficult to escape the conclusion that the close statistical link indicates some equally closely linked metabolic mechanism. It may also be relevant, sparing the premenopausal women as it does, to the pathogenesis of atherosclerosis and its relation with impaired glucose tolerance and diabetes (Epstein, 1967; Keen, Rose, Pyke, Boyns, Chlouverakis, and Mistry, 1965).

In conclusion, it would seem that, despite the intensive search for more fundamental mechanisms determining diabetes in man, hyperglycaemia remains its sine qua non. The normoglycaemic diabetic has yet to be described. The classical qualitative concept of diabetes mellitus has now been stretched to accommodate what appears to be more of a quantitative phenomenon; it seems probable that we shall have to change our concepts and the words we use to describe them. While individual case study will remain a major source of information, it is clear that properly conducted epidemiological studies 
have enormous potential in helping to explain this mysterious condition.

\section{REFERENCES}

Abrams, M. E., Jarrett, R. J., Keen, H., Boyns, D. R., and Crossley, J. N. (1969). Brit. med. J., 1, 599.

Bowen, A. J., and Reeves, R. L. (1967). Arch. intern. Med., 119, 261. Boyns, D. R., Crossley, J. N., Abrams, M. E., Jarrett, R. J., and Keen, H. (1969). Brit. med. J., 1, 595.

Cerasi, E., and Luft, R. (1967). Acta endocr. (Kbh.), 55, 278.

Epstein, F. H. (1967). J. Amer. med. Ass., 201, 795.

Hansen, R. Ø. (1965). Diabetologia, 1, 97.

Jarrett, R. J., and Keen, H. (1968). Communication to the Medical and Scientific Section of the British Diabetic Association, Aberdeen. Brit. med. J., in press.

Kamarit, J., and Laxová, R. (1966). Humangenetik, 3, 41.

Keen, H. (1963). Diabetes, 12, 406.

- , and Jarrett, R. J. (1967). Lancet, 2, 214.
$-,-1969)$. Modern concepts in the diagnosis of diabetes. In The New Management of Stable Adult Diabetics, edited by S. Weller. Thomas, Springfield, Ill.

-_, Rose, G. Pyke, D. A., Boyns, D. Chlouverakis, C., and Mistry, S. (1965) Lancet, 2, 505.

McDonald, G. W., Fisher, G. F., and Burnham, C. (1965). Diatetes, 14, 473.

Marble, A. (1967). Ibid., 16, 825.

Miller, M. Bennett, P. H. and Burch, T. A (1968). Biomedical. Challenges Presented by the American Indian. Scientific Publication No. 165, Pan American Health Organization, Washington, D.C.

Perley, M. J., and Kipnis, D. M. (1967). J. clin. Invest, 46, 1954

Prior, I. A. M., Rose, B. S., Harvey, H. P. B., and Davidson, F. (1966). Lancet, 1, 333 .

Pyke, D. A., and Taylor, K. W. (1967). Brit. med. J., 4, 21

Roberts, H. J. (1964). J. Amer. Geriat. Soc., 12, 423.

Siperstein, M. D., Unger, R. H., and Madison, L. L. (1968). J. clin. Invest., 47, 1973.

Steinke, J., Soeldner, J. S., Camerini-Dávalos, R. A., and Renold, A. E. (1963). Diabetes, 12, 502.

Vallance-Owen, J. (1964). Ibid., 13, 241.

West, K. M., and Kalbfleisch, J. M. (1966). Ibid., 15, 9.

Yalow, R. S., and Berson, S. A. (1960). Ibid., 9, 254. 